\title{
Deep Eutectic Solvent Reline - Highly Efficient Electrolyte For Stainless Steel Electropolishing
}

$\underline{\text { Anna Kityk }}^{1^{*}}$, Natalia Bannyk ${ }^{1}$, Olena Kun ${ }^{1}$

1. Department of physical chemistry, Ukrainian State University of Chemical Technology, UKRAINE, Dnipro, Gagarin ave. 8,

*E-mail: kitykanna7@gmail.com

New modern technology of surface treatment of stainless steel was shown. Deep eutectic solvent Reline was proposed as a highly efficient electrolyte for electropolishing of AISI 304. Anodic treatment of AISI 304 steel samples in Reline leads to an improvement in appearance and surface properties. Electropolished samples are characterized by low roughness, shiny surface, less wettability and as a consequence of higher resistance to corrosion.

Keywords - deep eutectic solvent, eco-friendly medium, electropolishing, cyclic voltammogram, roughness coefficient, wettability, contact angle.

\section{Introduction}

Well known that electropolishing improves the near surface chemistry of stainless steel $[1,2]$. Not only does it remove embedded particles and inclusions, it also improves the atomic ratios of the material's alloying elements. Electropolishing preferentially dissolves Iron from the material and leaves the surface with a higher relative concentration of Chromium. Upon exposure to Oxygen, this improved surface will form a thicker and more uniform oxide layer with enhanced corrosion resistance properties. Electropolished stainless steels are better suited to resist the onset of pitting corrosion, crevice corrosion, stress corrosion cracking, and microbiologically influenced corrosion.

«Traditional» electropolishing technologies use toxic mixtures of chemicals - concentrated solutions of sulfuric, hydrochloric, orthophosphoric, hydrofluoric, nitric acids with the addition of glycols, chromic anhydride, etc [3-7]. Such kind of electrolytes capable of destroying industrial equipment, harming the environment and human health. Moreover, chemically aggressive mixtures are not always effective and do not lead to the necessary improvement in the quality of functional materials (metals and alloys).

Modern low temperature ionic liquids - deep eutectic solvents (DESs) can be perfect alternative for traditional toxic electropolishing electrolytes. For example such DES as Reline (eutectic mixture of choline chloride and urea with molar ratio 1:2 respectively) are not only environmentally friendly, but also possess a number of very attractive properties: chemical, thermal, electrochemical stability, availability of components, ease of synthesis and relatively high as for ionic liquids electrical conductivity at high viscosity [8-11].

A unique combination of high electrical conductivity with high viscosity allows predicting significant success in the use of this electrolyte for the anodic treatment of metals and alloys.

The main goal of this work is to use complex approach for study of the principle possibility of using Reline as an electrolyte for highly efficient anodic treatment of austenitic stainless steel AISI 304.

\section{Experiment and Discussion}

The cyclic voltammogram (CVA) obtained for stainless steel AISI 304 in deep eutectic solvent Reline at temperature $20^{\circ} \mathrm{C}$ is shown in Fig. 1. Scanning of potential was carried out from the stationary value $-0.5 \mathrm{~V}$ in anodic region to the potential $\approx 9.5 \mathrm{~V}$ and then in cathodic region to the potential $\approx-3 \mathrm{~V}$ (potential scan rate was equal $2 \mathrm{mV} / \mathrm{s}$ ). As can be seen from CVA, 
in anodic region noticeable peak of dissolving current of steel sample is observed, after can be seen a long "passive" region. Passivation of a metal sample can be associated with the formation of protective oxides on the surface of stainless steel. Passive chromium and nickel oxides (these elements are part of the alloy AISI 304) can be formed on the surface and prevent further sample dissolution.

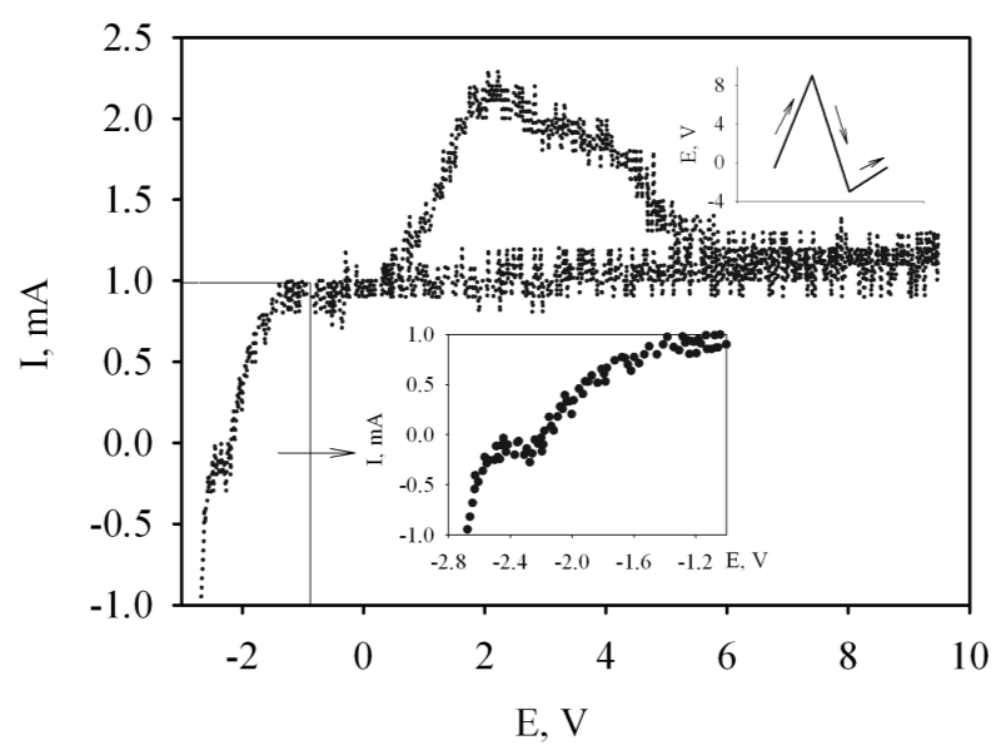

Fig.1. CVA of AISI $304\left(\mathrm{~s}=4 \mathrm{~cm}^{2}\right)$ in deep eutectic solvent Reline

In cathodic region (Fig. 1) peak of $\mathrm{Fe}^{2+} \rightarrow \mathrm{Fe}^{0}$ electroreduction current is observed. Further increase of current corresponds to other electroreduction reactions for solvent components.

Based on information obtained from the CVA for the electropolishing process in potentiostatic mode several potential values were selected: 1, 1.5, 2, 4, 6 and $8 \mathrm{~V}$. Image that illustrated of 20 minutes electropolishing effect for AISI 304 samples at selected potentials is shown in Fig. 2

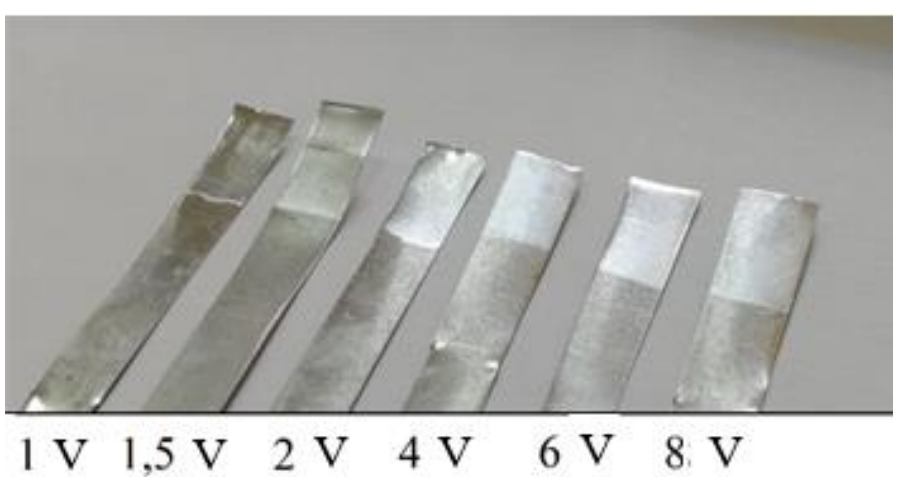

Fig. 2. AISI 304 samples after the electroplating process at different potentials in Reline solvent (processing time $20 \mathrm{~min}$.)

As can be seen from Fig. 2 with the increase of the electroplating potential the surface of the samples becomes shinier. When polishing potential $\mathrm{E} \geq 2 \mathrm{~V}$ the surface of AISI 304 samples acquires an attractive silver-gray tint. It shod be noted that after electropolishing of AISI 304 samples, not only the appearance of the surface changes, but also the properties.

Electropolishing of stainless steel samples (AISI 304) in Reline solvent leads to a decrease in surface roughness (Fig. 3). During the anodic process dissolution of irregularities and other 
defects take place; deep scratches and traces of rolled steel sheet disappeared after polishing treatment.

Moreover it can be argued that changes in the surface layer of the samples associated with changes in the surface composition of the alloy.

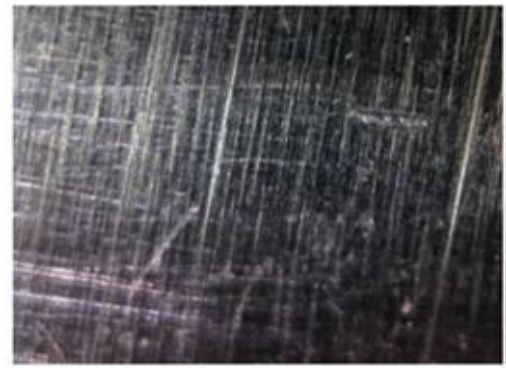

before

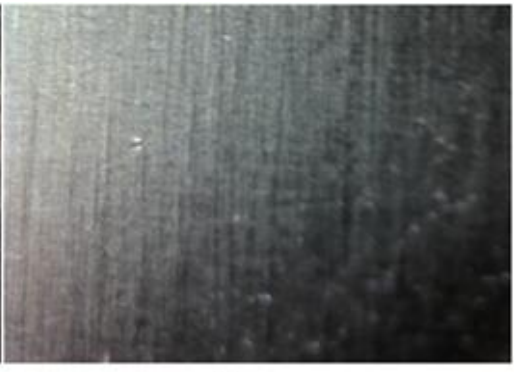

after

Fig. 3. Optical microscope SyperEyes B800 $(\times 500)$ photo of AISI 304 sample before and after the electropolishing process in Reline $(\tau=20$ min., $\mathrm{E}=8 \mathrm{~V})$

Changes in wettability properties of AISI 304 surface after the polishing process was found (see Fig. 4). As can be seen from Fig. 4, the shape of water drop on unpolished and polished surface is noticeably different. Contact angle for AISI 304 polished sample is about 2 times more than contact angle for unpolished sample.

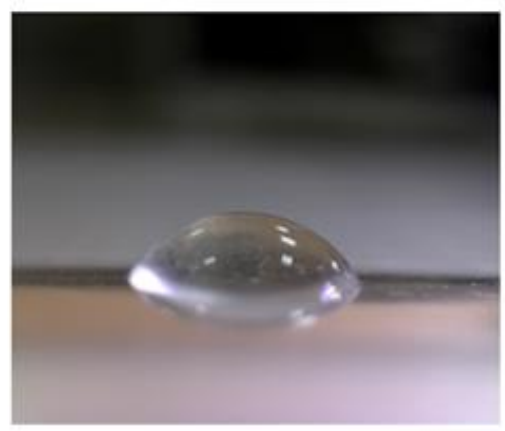

before

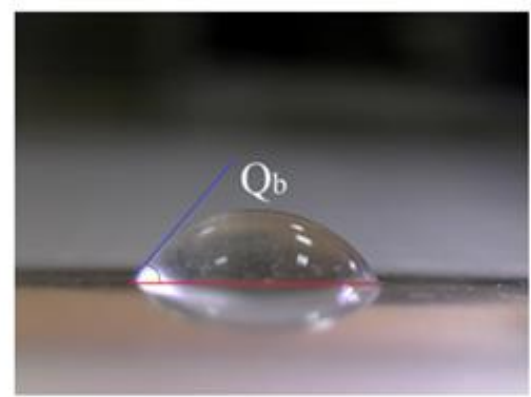

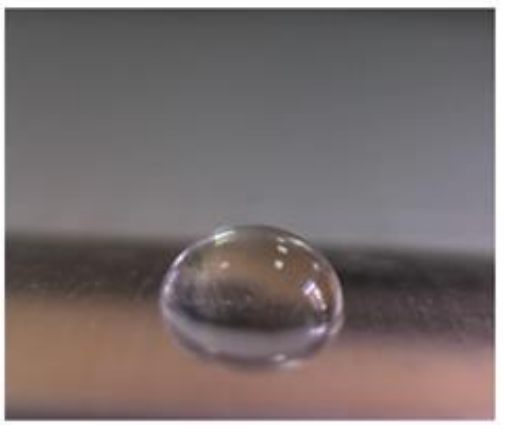

after

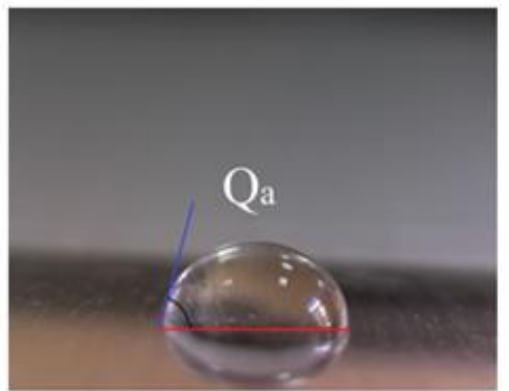

Fig. 4. A drop of distilled water on unpolished (before) and polished (after) surface of AISI 304 in Reline (electropolishing conditions $\tau=20$ min., $\mathrm{E}=8 \mathrm{~V}$ )

Thus, electropolishing of stainless steel leads to an increase in the hydrophobic properties of AISI 304 surface. As a rule, an increase in the surface hydrophobicity may lead to an improvement in the corrosion resistance of the material. Therefore, it should be expected that AISI 304 stainless stee after electropolishing in Reline will be more resistant to corrosion than unpolished. 


\section{Conclusion}

It was shown that environmentally friendly electrolyte Reline can be used as a promising alternative to traditional toxic stainless steel polishing electrolytes. AISI 304 samples after polishing in Reline are characterized not only by a uniform shiny surface, but also by improved functional properties. This type of anodic treatment helps to decrease the surface roughness of stainless steel, increase hydrophobicity and improve corrosion resistance.

\section{Acknowledgments}

The authors of the article thank professors F. Danilov and V. Protsenko for the discussion of the results. This work is done as part of the young scientists research work "Highly effective anode treatment of bioresistant alloys for medical propose with using ecologically friendly ionic liquids of the new generation" with registration number 0119 U002001 which is funded by the Ministry of Education and Science of Ukraine.

\section{References}

[1] C. C. Shih, C. M. Shih, Y. Y. Su, L. H. J. Su, M. S. Chang, S. J. Lin, "Effect of surface oxide properties on corrosion resistance of 316L stainless steel for biomedical applications", Corrosion Science, vol. 46, no. 2, pp. 427-441, 2004.

[2] B. Chatterjee, "Science and Industry of Electropolishing", Galvanotechnik, vol. 71, no. 1, pp. 71-93, 2015.

[3] L. Ponto, M. Datta, D. Landolt, "Electropolishing of iron-chromium alloys in phosphoric acid - sulphuric acid electrolytes", Surface and Coatings Technology, vol. 30, pp 265-276, 1987.

[4] M. Datta, D. Landolt, "Electropolishing of iron-chromium alloys in phosphoric acid sulphuric acid electrolytes", Surface and Coatings Technology,. vol. 30, pp. 265-276, 1987.

[5] V. B. Singh, U. Arvindt, "Electrodissolution of AISI 304 stainless steel in concentrated acids leading to electropolishing", Indian Journal of Chemical Technology, vol. 2, pp. 211216, 1995.

[6] S.-J. Lee, J.-J. Lai, "The effects of electropolishing (EP) process parameters on corrosion resistance of 316L stainless steel”, Journal of Materials Processing Technology, vol. 140, no. 1-3, pp. 206-210, 2003.

[7] P.J. Núñez, E. García-Plaza, M. Hernando, R. Trujillo, "Characterization of Surface Finish of Electropolished Stainless Steel AISI 316L with Varying Electrolyte Concentrations", Procedia Engineering, vol. 63, pp. 771-778, 2013.

[8] Q. Zhang, K. De Oliveira Vigier, S. Royer, F.Jérôme, "Deep eutectic solvents: syntheses, properties and applications", Chem. Soc. Rev., vol. 41, no. 21, pp. 7108-7146, 2012.

[9] E. L. Smith, "Deep eutectic solvents (DESs) and the metal finishing industry: where are they now?", Transactions of the IMF. The International Journal of Surface Engineering and Coatings, vol. 91, no. 5, pp. 241-248, 2013.

[10] A. Paiva, R. Craveiro, I. Aroso, M. Martins, R. L. Reis, A. R. C. Duarte, "Natural deep eutectic solvents - solvents for the 21st century", ACS Sustainable Chemistry \& Engineering 2, vol. 5, pp. 1063-1071, 2014.

[11] E. L. Smith, A. P. Abbott, K. S. Ryder, "Deep eutectic solvents (DESs) and their applications", Chemical reviews, vol. 114, no. 21, pp. 11060-11082, 2014. 